\title{
The Psychology of Faculty Demoralization IN THE LIBERAL ARTS: \\ BURNOUT, ACEDIA, AND THE DISINTEGRATION OF IDEALISM
}

by

\author{
Steven J. Bartlett \\ Visiting Scholar in Psychology, Willamette University \\ and \\ Senior Research Professor, Oregon State University \\ Website: http://www.willamette.edu/ sbartlet
}

KEYWORDS: teacher burnout, acedia, teaching of liberal arts, liberal arts values

This paper was originally published in New Ideas in Psychology, Vol. 12, No. 3, 1994, 277-289. The original paper may be obtained from http://www.journals.elsevier.com/new-ideas-in-psychology/. This electronic version supplements the journal's text with internet-searchable keywords and is the author's original version. For readers wishing to cite the pagination in the journal, the journal's page numbering is indicated in braces: for example, $\{278\}$ appears at the beginning of the journal's text on page 278 .

The author has chosen to re-issue this work as a free open access publication under the terms of the Creative Commons Attribution-NonCommercial-NoDerivs license, which allows anyone to distribute this work without changes to its content, provided that both the author and the original URL from which this work was obtained are mentioned, that the contents of this work are not used for commercial purposes or profit, and that this work will not be used without the author's or his executor's permission in derivative works (i.e., you may not alter, transform, or build upon this work without such permission). The full legal statement of this license may be found at

http://creativecommons.org/licenses/by-nc-nd/3.0/legalcode

(c) $(1)(9)$

(C) Steven James Bartlett, 2014 
[Completed Nov. 18, 1992]

Published in New Ideas in Psychology, Vol. 12, No. 3, 1994, 277-289.

\title{
The Psychology of Faculty Demoralization IN THE LIBERAL ARTS:
}

\section{Burnout, ACEDIA, AND THE Disintegration OF IDEALISM}

\author{
by \\ Steven J. Bartlett \\ Senior Research Professor, Oregon State University \\ and \\ Visiting Scholar in Psychology and Philosophy, Willamette University
}

\begin{abstract}
Work was for him, in the nature of things, the most estimable attribute of life; when you came down to it, there was nothing else that was estimable. It was the principle by which one stood or fell, the Absolute of the time; it was, so to speak, its own justification. His regard for it was thus religious in its character, and, so far as he knew, unquestioning.
\end{abstract}

— Thomas Mann, The Magic Mountain

Without work all life goes rotten. But when work is soulless, life stifles and dies.

- Albert Camus ${ }^{1}$

$\{278\}$ Social psychologists hope to take notice of potentially significant changes in cultural values and their effects in personal life, while these changes are still subtle. During the last three decades, a gradual trend in higher education and, in particular, higher liberal arts education, has been the focus of attention among people concerned with the present and 
the future of the university. Some of this attention has been directed toward expressions of discontent and of high stress among liberal arts faculty. The informal descriptive name for this phenomenon has been faculty burnout, which forms a part of more general research relating to career burnout.

A good deal has now been written about career burnout, less about disillusionment among university faculty, and still less about the specific problems experienced by liberal arts faculty. Most of the more general research dealing with stress in the academic world has held that faculty burnout is due to the gradual erosion of a usually young professor's idealism in an environment lacking in gratification. The reasons given for this lack of gratification are multiple. In general they tend to fall into two categories: the frustrating blocks that young faculty often encounter when they wish to bring about changes in the way education is managed or offered to students, and the general absence of direct recognition and approval received by younger faculty from their administrations and older colleagues. Burnout among specifically liberal arts faculty has been viewed from this perspective that emphasizes the frustration similarly felt by usually idealistic and usually young faculty, who do not receive the acceptance and appreciation they need to sustain them. This point of view has been applied generically, that is, without an attempt to discriminate differentiating problems, to burnout experienced by faculty in a wide range of disciplines. There has been no attempt to study the specific psychology of faculty demoralization in the liberal arts, which, I suggest here, is substantively different from burnout in other professions.

This paper tries to widen our understanding of the psychology of faculty demoralization in the liberal arts. The demoralization of its faculty in higher education today is a phenomenon that is not on a par with career burnout in other professions. The frustration of youthful idealism and the absence of sufficient, direct, and personal appreciation from one's senior colleagues and from superiors in the college bureaucracy do certainly wear down young liberal arts faculty. But the demoralization that they, as well as many of their older colleagues, feel is more than this. 


\section{The Nature of Career Burnout}

Career burnout, in or outside of the academy, is fundamentally connected with the human need for meaning. When a person's work supports and strengthens the perception of meaningfulness, those who are highly motivated will excel; but when their work detracts from and even undermines their ability to find meaning in what they do, burnout is only a matter of time. Burnout is not the same thing as work stress, depression from overwork, or alienation, though it usually involves these. One of the clearest general descriptions of career burnout has been given by Ayala Pines and Elliot Aronson:

$\{279\}$ Burnout is formally defined and subjectively experienced as a state of physical, emotional, and mental exhaustion caused by long-term involvement in situations that are emotionally demanding. The emotional demands are most often caused by a combination of very high expectations and chronic situational stresses. Burnout is accompanied by an array of symptoms including physical depletion, feelings of helplessness and hopelessness, disillusionment, and the development of a negative selfconcept and negative attitudes toward work, people involved in work, and life itself. In its extreme form burnout represents a breaking point beyond which the ability to cope with the environment is severely hampered. ${ }^{2}$

The study by Pines and Aronson suggests that there is a psychological profile which is often typical of people who experience career burnout: More than does the average person,

- they tend to be idealistic, in that they expect their work to give their lives a sense of meaning- "burnout most often happens to people who initially cared the least about their paychecks";

- they tend to be especially caring about their work and its value, sometimes so much so that they regard their work as a "calling"; and

- they are often highly motivated to achieve, in a way that goes beyond routine high achievement, due to a strong and unquestioned belief that success in one's discipline is closely associated with one's worth as a human being.

People with these qualities tend to burn out when their work environment has these characteristics:

- It frustrates, and may completely block, their aspirations: The frustration they experience, given their high expectations and need for meaningful work, soon erodes their spirit. 
- Their work offers minimal personal rewards in the context of inescapable stresses that cannot be lessened or changed.

- Their work load is excessive, on the one hand, or else work itself does not provide sufficient challenge, because they are overtrained and do not feel well utilized.

When their work comes to have little or no meaning, and the stresses of work day after day outweigh its rewards, burnout becomes inevitable. Pines and Aronson have found that the victims of career burnout feel one or more of these forms of exhaustion or depletion:

- mental exhaustion: difficulty concentrating, impaired creativity, and negative attitudes toward one's self, others, one's work, and life generally;

- emotional exhaustion: feelings of helplessness in situations they cannot control, entrapment, and depression;

- physical exhaustion: chronic fatigue, lowered resistance to illnesses, headaches, neck and back pain, eating disorders, and problems in sleeping.

Unfortunately, the unreflective tendency among the majority of mental health practitioners is automatically to pursue a course of treatment that encourages the person to adjust to the existing work environment. Pines and Aronson's study opposes this tendency by emphasizing that the major causes of burnout reside in the work environment itself. Their outlook is hopeful, even if unrealistic: "Since we view environments as more amenable to change than persons' personalities, we $\{280\}$ prefer to direct our efforts to work environments." ${ }^{4}$ They believe that it is the work environment that must be changed, rather than the individual:

How individuals perceive the cause of their burnout and attribute the "blame" has enormous consequences for action. If they attribute the cause to a characterological weakness or inadequacy in themselves, they will take a certain set of actions: quit the profession, seek psychotherapy, and so forth. However, if they see the cause as largely a function of the situation, they will strive to change the situation to make it more tolerable, a totally different set of remedial actions. ...[O]ur work has made it clear that, in the vast majority of cases of burnout, the major cause lies in the situation. ${ }^{5}$ 
It is not my purpose to pull the pendulum to one side in this individual versus environment debate. However, it is important to underscore the fact that psychological treatment for career burnout, in its one-sided focus upon individual adjustment, tends to avoid placing responsibility upon the environment.

When career burnout becomes most severe, the individual becomes clinically depressed, and may then benefit from some variety of treatment. If, indeed, career burnout is to a great extent environmentally caused, then treating clinically depressed individuals who have become burned out in their careers exclusively by means of individual adjustment therapies is likely to be both inappropriate and, as we will see, potentially injurious to them.

This is especially true of the burnout of faculty in the liberal arts, as the remainder of this paper attempts to show.

\section{The Concept of Situational Depression}

Of the theories advanced to explain depression, among those least in vogue among clinicians is the theory of situational depression. To claim that depression is situational is equivalent to blaming environment for an individual's impairment. This directly conflicts with the individual adjustment bias of most current theories of psychotherapy. Because the majority of psychologists, psychiatrists, and social workers today believe that clinical depression, often associated with serious career burnout, is an illness that has its causal basis in the individual, the treatment that is favored by them seeks to change the person-specifically attitudes or other mental and emotional dispositions, or his neurochemistry, or all of these. The alleviation of depression, in this view, is a matter of treating the individual-by helping him better to adjust to his environment. The help given is of the form that would adjust attitudes and often biochemistry until a more compatible, comfortable fit between individual and environment is accomplished. Seen from this point of view, clinicians serve the purposes of social adjustment and conditioning: They help people to continue to carry on with their social responsibilities.

The situational understanding of depression is the less popular province of the social psychologist, who is less involved in treatment of individuals, and more in writing articles of this kind. Situational depression is a concept with comparatively few adherents, because it stresses environmental causes of depression, which are, $\{281\}$ Pines and Aronson's 
optimism notwithstanding, much less easily changed than may be the attitudes and biochemistry of a particular person. And certainly, from the standpoint of the evaluation of therapeutic effectiveness, efforts to modify the environment are intrinsically less amenable to the strictures of experimental control.

In terms of the question, whether its origin is situational or individual, studies of the phenomenon of career burnout have been both moderate and ambivalent. The majority describe burnout and its treatment in individual psychological terms, although they occasionally and vaguely allude to environmental causes. As yet there has been virtually no clarification of the question, to what extent burnout among faculty is a problem due to differing individual sensitivities, and to what extent it is situational. Certainly a more balanced and comprehensive knowledge of burnout requires a better understanding of its situational basis.

\section{The Situation in the Liberal Arts}

I consider reality to be the thing one need concern oneself about least of all, for it is, tediously enough, always at hand while more beautiful and necessary things demand our attention and care. Reality is that which one must not under any circumstances worship and revere, for it is chance, the refuse of life. And it is in no wise to be changed, this shabby, consistently disappointing reality, except by our denying it and proving in the process that we are stronger than it.

$$
\text { — Hermann Hesse, "My Life: A Conjectural Biography" }
$$

The point of view advanced in this section is phenomenological, a point of view that is fundamentally one of descriptive, definitional logic, rather than empirical observation derived from consensus taking. Certainly, the nature and goals of the liberal arts can be interpreted in many ways; my purpose here is to show how, given a certain traditional, even classical, conception of the liberal arts, burnout among faculty who hold that conception in today's universities is a phenomenon that is to be expected, is understandable, and, ironically, should be judged as a sign of mental health on the part of the affected individuals. These consequences follow, I submit, strictly from a logic of description. But they are human consequences, not of a purely logical variety, which bring pronounced human suffering with 
them. The purpose in developing the argument that follows is to provide a clearer context in which the victims of liberal arts demoralization can understand and accept themselves, and in terms of which their sometimes puzzled colleagues and administrators perhaps may acquire a deeper measure of empathy and support for their plight.

For this purpose, the reader will need to suspend [or bracket] his or her own conception of the nature and goals of the liberal arts, if it differs, and, for the purposes of argument, to consider with as much intellectual sympathy as can be summoned the human sequellae of the stipulative descriptions that follow.

There is a population of faculty in the liberal arts who, sometimes without self-conscious analysis, see themselves and their discipline in more or less classical terms: That is, they hold a reasonably well-defined set of beliefs about the fundamental purpose of liberal arts study, and perhaps a slightly less well-formulated $\{282\}$ conception of their role in its teaching and scholarship. Among these beliefs are likely to be found convictions similar to these:

The liberal arts, or artes liberales, are essentially distinct from the servile arts, or artes serviles, both in kind and in value, in certain ways.

- The servile arts are mundane, and of a chore-like nature, concerned as they are with the impermanent worldly trappings of monetary success and practical effect. The liberal arts, in contrast, intend to liberate the individual from the concerns of the practical, material universe, and to open for him or her dimensions of human experience that are qualitatively different.

- These dimensions of experience comprise a separate or distinguishable universe of meanings, perceived as a source of the significance of servile life. Insofar as this is the case, from the standpoint of this derivational basis for human meaning, the universe to which the liberating arts provide access is hierarchically superior to the lower-order world of servile pursuits. - This is not a matter of marshalling objective and empirical facts, but, again, of stipulative, definitional logic. It has the form, "If one understands by 'liberal arts' the following..., then ... is a psychological consequence."

- In the perception of the classical liberal arts scholar, human beings are unequally endowed in both their practical capacities and in their personal abilities to gain access to this second-order, higher reality. Their practical capacities differ because of differences in personal taste and inclination, as well as in their opportunities to develop liberating skills. On the one hand, this can be a simple matter of individual preference, but it can also reflect a poverty of opportunity to attend top-notch institutions of higher learning, to acquire libraries of fine books, of musical recordings, collections of art, etc., as well as the scarcity of time to cultivate liberal pursuits. On the other hand, personal abilities 
differ as a result of inborn talent, learned interest, and intellectual, spiritual, or aesthetic capability.

- Not infrequently, individuals who are particularly well-suited to liberal arts study are illsuited, or not suited at all, to other professions, just as the opposite is true. Like Thales, who, as popular legend would have it, fell into a well because his eyes were fixed on the stars, traditional liberal arts scholars tend not to be adept do-it-yourselfers in the material world; they tend not to fit the corporate mold; their psychological and personal profiles do not accord with the practical needs of reality's work-force.

Partly as a result of their accurate self-assessment, some liberal arts scholars feel drawn ineluctably to their chosen profession with either something akin to a sense of mission, or a more self-effacing acceptance that this is all they can do with competency. Their sense of mission relates to their perception that meaning in the transitory practical world is ultimately derivative from an enduring universe of more permanent realities.

These are some of the convictions that identify the personal point of view of what I have termed the classical liberal arts scholar. As a personal point of view, it is inherently deliminative and judgmental. The lines of meaning are pre-drawn for such a scholar; he fits into a bi-partite reality in a non-ambidextrous fashion: where he can touch his finger to his nose with consummate skill in one dimension, he $\{283\}$ often is completely at a loss in everyday life. He is both endowed with a gift, as well as the victim of a disability. He can see in the world of the blind, but blunders blindly in the midst of those whose vision is mundane.

He is also judgmental, since his perspective is essentially elitist and non-egalitarian. For him, however, elitism and the natural rights of man are not in themselves necessarily political issues, or manifestations of personal arrogance, but facts in a life-world that is constituted as it is. This is the province of phenomenological psychology's descriptive interest in the logos of the psyche, a concern to make explicit the regulative principles of a particular life-world. That there exists a higher and a lower reality is as evident to the classical liberal arts scholar as that automobiles emit pollution is to the man on the street. It is not a relevant matter of funding empirical studies with double-blind control groups to determine whether or not there is a genetic basis for liberal arts interest, talent, and skill. Reality for the classically paradigmatic liberal arts scholar simply comes with built-in indications of what is higher and what is lower.

Unfortunately for him, the political sensitivity of other men and women is easily ruffled. His in principle innocent perspective, which provides the scholar with a sense of balance and orientation toward what for him is most meaningful, is capable of being used against him by 
the politically driven. Certainly elitism and a repudiation of egalitarian principles can lead to overweening pride and abusive social evils, but this fact, with its historical, political, educational, and highly emotional overtones, is out of place in this discussion, whose intent is purely to describe the world as experienced by the classically disposed liberal arts scholar.

With this descriptive sketch before us, we turn to look at the work environment as it is perceived by the traditional liberal arts professional. Objectively and in the shared world of fact, the university has, as is evident everywhere, changed considerably from the time of Newman, who had less to complain of then. Josef Pieper has come and gone, Allan Bloom briefly stirred a certain amount of dust, but, in the end, education today is no longer "higher" in the meaning that traditionally was attributed to it. Certainly, there is more that could be said in this connection here, but much has been said before elsewhere, with comparatively little effect, by Robert M. Hutchins, Russell Kirk, and others who have keep their intellectual company.

Instead, here we consider the actual work environment, as it is makes up the practical context for the efforts of the classical liberal arts scholar. A single aspect of his environment affects him most deeply: It is delimited by the values, interests, and scope of vision shared by the majority of his students, with which he is in daily contact. At the same time, it is a perspective often advocated by his university administrators and many of his colleagues.

Contact with students comprises the main context for his professional exertions, for it is their talk that fills his ears, their papers that occupy his eyes, and their values and interests that, in the end, give him pause for reappraisal. It is what the majority care most about, frequently to the exclusion of all else, that needs to be considered dispassionately, in order to understand the phenomenon of liberal arts demoralization. Previously in this journal, I have analyzed the phenomenon of "work-engendered depression," a condition due to an exclusionary focus upon $\{284\}$ work, money, and things. ${ }^{7}$ The culturally or spiritually depleted universe of people who inhabit a world of total work leads, I have tried to show, to a variety of depression little understood today.

Centuries ago, however, the condition was clearly acknowledged and comprehended with a remarkable degree of clarity. It was called acedia by the Scholastics. Acedia is no more, no less than a form of psychological malnutrition in which an individual, or an entire people, has lost contact with the very realities that concern the classical liberal arts scholar. These realities may be of a spiritual kind, they may be aesthetic, or they may be theoretical in nature, any of 
which can liberate a man or woman from the confines of a soulless dedication to the workplace, shopping malls, and financial planning.

More than any other single group, college students today exhibit the symptoms of acedia: In the impoverished state of mind brought about by an exclusionary relish for work and its financial rewards, acedia leads to despair, which the Scholastics conceived of as an unwillingness to be fully human. They saw this form of despair as a condition of demoralization that presents an impasse to the realization of one's full human potential. From this point of view, the despair of acedia is a barrier that stands between the man or woman who is a slave to the world of work and money, and higher values. It is a despair that is an impairment, preventing people from transforming the mundane. The result is that their universe of concerns excludes all that is not mediocre.

This constricted human outlook brings with it the filiae acediae, the partners of despair in this narrowed universe, identified long ago by Aquinas. ${ }^{9}$ They include: (i) a heightened need for distraction and stimulus; (ii) inner restlessness; (ii) instability of place or purpose; (iv) an unfocused, unanchored, indiscriminate interest in any and all things; (v) the urge to scatter oneself in many pursuits; (vi) a repudiation, indifference toward, and neglect of higher values; (vii) antagonism toward higher values; (viii) resentful rebellion against those who represent and seek to cultivate higher ends; and (ix) a deeply seated resistance or even hatred for whatever may be capable of elevating man above the trivial, the fatuous, the superficial.

These are symptoms of individuals and of societies today that have lost contact with culture, with cultus, with the cultivation of liberating arts. Where for the Scholastics, acedia was a disease of the spirit, today it would appropriately qualify as a mental disorder. Acedia is essentially a disability of values, that leads to a certain impairment of mental faculties, whether intellectual, aesthetic, or spiritual. It is an incapacity to cultivate leisure of a specifically liberating kind. Assuredly, the fault for acedia does not in the main lie with students themselves, but with the society and with the families that have transmitted to them the incapacitating blinders they wear.

To return to the life-world of the classical liberal arts professor: He sees before him, day in and day out, legions of students who manifest the symptoms of acedia. Most are young; but acedia has already taken firm hold in their minds, hearts, and vocationally compulsive tunnelvision. The consequences upon the classically oriented liberal arts professor are equally pronounced, for he is caught in the never-ending $\{285\}$ ordeal of the musician who must 
perform for audiences who are not receptive, and may be openly hostile, to music. The values and skills that he seeks to impart, which define and open access to a reality of a higher order, fall on ears that have been deafened not only by loud rock music, but by the other dulling effects of the narrowed vision of university education in the service of job acquisition.

\section{Situational Depression of Faculty in the Liberal Arts}

I have tried to describe a certain type of individual, whom I have called the classically inspired liberal arts professor, and, as seen through his eyes, his audience today. When the liberal arts professor is fully committed to his subject and to the values of its study, and when his audience unquestioningly focuses on vocational and monetary values to the exclusion of all else, the work environment of the professor will lead to situational depression of a particular kind. His environment stands in direct opposition to his sense of self: His students are victims of a disease of the spirit, acedia, which blocks them from cultivating the higher learning that he would teach. Moreover, the liberal arts professor is trapped by his work environment in the academy, perhaps believing his teaching and research to constitute a personal calling, on the one hand, while alternatives to his academic profession bring him face to face with the shortcomings he experiences in "lower reality," on the other.

This is a classically double-binding situation: The liberal arts professor is damned if he does, and damned if he doesn't. A well-acknowledged cause of depression is just this sort of entrapment in a situation that brings deep pain, and from which the only perceived escape is itself severely painful.

Career burnout in other professions does not involve this complex dynamic or the distressing and profound conflict both with one's personal sense of identity and with the conception of one's role in the world.

\section{Adjustment Disorders and the Liberal Arts}

I spoke earlier of the tendency of mental health providers today automatically to implement individual adjustment therapies in connection with cases of career burnout, and I 
mentioned in passing that individual adjustment therapy for liberal arts professors can be injurious. I would like to return to this subject briefly.

The only DSM-IIIR diagnostic classification that seems to apply to the situational depression of liberal arts faculty is "adjustment disorder, with work inhibition" (code 309.23):

The essential feature of this disorder is a maladaptive reaction to an identifiable psychological stressor.... The maladaptive nature of the reaction is indicated...by impairment in occupational (including school) functioning.... [T] he predominant manifestation is an inhibition in work...occurring in a person whose previous work...performance has been adequate. Frequently there is a mixture of anxiety and depression..$^{10}$

Two judgments embedded in this classification need to be made explicit: that the condition is a "mental disorder," and that the disorder is "maladaptive." These $\{286\}$ judgments determine the treatment that situationally depressed liberal arts faculty receive if they seek psychological or psychiatric help.

If we are willing to move beyond the limits prescribed by the current classification of mental disorders, what certain liberal arts faculty experience today is most akin to demoralization, rather than maladaptive mental illness. This demoralization is a secondary dysfunction, to speak clinically, acquired as a result of long-term, inescapable exposure of university faculty to acedia, both in their students and embodied in their administrations. Morale is a matter of spirit, certainly of emotional and mental health. When a situation is destructive of morale it is destructive of an individual's spirit, depleting the energy and desire to realize his or her human potential.

As we have seen, the Scholastics believed that the despair to which acedia leads has precisely this life blocking effect. In much the same way, the secondary despair of the liberal arts professor is destructive of his potential; he is caught in a work environment in which, in his perception, the members of his audience-his customers, in this market-oriented society-are functionally impaired, in the sense of being mentally handicapped (intellectually, aesthetically, or spiritually), so as to be incapable of the cultivation he aspires to encourage in them.

The demoralization of liberal arts faculty that is in question here is not a matter of mental illness; there is no impairment of mental faculties, as there is in the condition of acedia. There 
exist no directly applicable categories in the classification system of psychotherapy with which to label this situational by-product of acedia. Perhaps the closest is the disorder of demoralization that Viktor Frankl called "noögenic neurosis," Frankl's term for existential frustration that occurs when a person's will to meaning is blocked. ${ }^{11}$ The suffering that such frustration brings is the result of a conflict between opposing values-in the present instance, the conflict between the deeply rooted commitments of the liberal arts scholar, understood as essentially absolutist, hierarchical, and elitist—and the vocational, materialist, relativist, and monetary values that circumscribe the interests of the majority of his students.

Other than Frankl's work, George A. Kelly's theory of personal constructs offers a framework in terms of which liberal arts demoralization may be understood. Kelly's therapeutic orientation is, like his contemporary J. H. van den Berg's, ${ }^{12}$ phenomenologically sensitive to the world as a person experiences or construes it. Speaking of his clients, Kelly commented: "We have observed only that they do what they do because their choice systems are definitely limited." ${ }_{13}$ The choices open to a person are a reflection, according to Kelly, of the individual's personal constructs, of the "channels of thought" that he uses to construe events. Kelly saw these channels as a maze that each person builds and calls his own.

The labyrinth is conceived as a network of constructs, each of which is an abstraction and, as such, can be picked up and laid down over many different events in order to bring them into focus and clothe them with personal meaning. ${ }^{14}$

Kelly would probably have portrayed liberal arts demoralization as acute $\{287\}$ frustration over the narrowed choices that exist from the point of view of the liberal arts professor. When all perceived alternatives are without real hope, demoralization becomes inevitable, appropriate, and understandable. For the classical liberal arts professor, the only alternatives not destructive of self are: to continue to profess a set of values to an otherwise disposed audience, or to leave the only work environment suited to the kind of person he believes himself to be. It is a dilemma of assured discontent.

"Axiological demoralization," if not such a mouthful, may come closer to an accurate name for impairment due to the experience of incompatibility between an individual's most cherished values and those that define his environment. Mircea Eliade refers to the axis mundi of certain primitive societies, that both anchors the meaning of the individual lives of 
members of the society, and gives direction to their activities..$^{15}$ Axiological demoralization is the experience of the loss of the power of an individual's axis mundi to provide life with meaningful direction. Loss of religious faith would be an example, when this loss leads to despair.

The demoralization of faculty in the liberal arts, for professors whose axis mundi is the cultivation of liberating skills and study, can lead to clinical depression. Yet, because of the unquestioned application of individual adjustment therapies to alleviate depression, which I have commented on earlier, treatment of axiological demoralization is likely to be injurious to the person.

The reason is straightforward: For anyone whose sense of purpose in living, whose sense of personal identity and capacity for fulfillment are fundamentally tied to liberating skills and a vision of enduring, ideal, non-material realities, adjustment to the workplace, when the academic world of today is involved, is the equivalent of destruction of self, or self-mutilation: Huxley's metaphor applies squarely here-that a person should have his eyes put out in order to fit into a society of the blind. Certainly this is prescribed adaptation, but it does not accord, fortunately, with the principles of humanitarian practice that we preach.

The application of individual adjustment therapies leads to just such an effect on those whose vision lifts them out of the mundanity and mediocrity of the everyday world.

\section{Treatment for Liberal Arts Demoralization}

Strictly from a phenomenological point of view, two factors play a central role in situational depression among liberal arts faculty: their claim to a higher reality to which the rest of the world is now largely blind, and the resistance and even opposition to their values by the students and university administrators who are victims of acedia. Outside the special context of the liberal arts, we may see with greater clarity that psychiatry has been used in some countries to label politically dissident views "illnesses." Occasionally, a Thomas Szasz will remark on the similarity closer to home. We live in a society that has become ideologically hysterical about the evils of elitism and the need for a homogeneously endowed populace. This is the social $\{288\}$ context within which situational depression of liberal arts faculty is assessed and treated. It makes sense that our society should be incapable of real sympathy toward the situationally-based demoralization of liberal arts faculty. It is 
understandable that in their response to prevailing social values, mental health professionals should classify the demoralization of liberal arts faculty as a maladaptive mental illness. This is the expected reflex of a society blind to liberating values.

If we take the idea seriously that faculty demoralization in the liberal arts is neither maladaptive nor in the nature of a mental disease, but instead regard it to be a phenomenologically appropriate response to a destructive situation, there are, unfortunately, few realistic alternatives for treatment available. Ayala and Pines would prescribe changing the environment. But the environment here is contemporary higher education itself, which, in the perception of the classical liberal arts scholar, has lost the ability to discriminate higher from lower, and which has succumbed to vocationalism. Today's anti-elitist, relativist, equality of abilities ideology offers no socially authorized niche for the liberal arts scholar. His elitism is mistaken as arrogance, his avowal of higher-order realities is misconstrued as subversive, and his acceptance of unequal and diverse abilities, talents, and interests in his students is misinterpreted as a repudiation of democratic principles.

From the edge of this precipice, the outlook is grim, for the liberal arts scholar is no more, no less than an anachronism, and for many, an undesirable anachronism. He is simply irrelevant to the social order and to the values of the day.

Given that the dynamic of the current social and educational mind-set is strongly selffueling and resistant to change, treatment for the liberal arts scholar suffers from a paucity of plausible alternatives. Two that do not fundamentally compromise the scholar's values and role in living come to mind: The first alternative might be to cultivate an essentially private monasticism within the academy, viewing his life and work as preserving a past culture for an eventual possible future, when culture may once again become possible. But walling oneself off is an abysmally alienating path to take, and because of its alienating character is a dubiously helpful treatment for a depressive condition.

The other alternative - as with any instance of situational depression in which the environment cannot be substantially changed-is to leave the situation that leads to demoralization, and to cultivate scholarship outside of the academy. To do so requires an inner capacity to motivate oneself to liberating ends, in spite of the practical demands of lower reality. And yet it may be the only true path open that will permit the liberal arts scholar today to maintain his spiritual health, free from despair. Although this choice involves physical distancing from the academic world, for some it may be significantly less 
alienating than the first alternative, because exposure to the pathology of acedia has been reduced.

Liberal arts demoralization is, in other words, the Huxlean epiphenomenon of the general disintegration of idealism. The values that sustained classical idealism, and the men and women who gave their lives for it, are gradually disappearing. The increasingly few scholars in whom classical liberal arts ideals remain alive, and whose morale has become eroded, may want to recall Russell's counsel:

\{289\} Let us admit that, in the world we know, there are many things that would be better otherwise, and that the ideals to which we do and must adhere are not realized in the realm of matter. Let us preserve our respect for truth, for beauty, for the ideal of perfection which life does not permit us to attain, though none of these things meet with the approval of the unconscious universe.... In action, in desire, we must submit perpetually to the tyranny of outside forces; but in thought, in aspiration, we are free, free from our fellow men, free from the petty planet on which our bodies impotently crawl, free even, while we live, from the tyranny of death. Let us learn then, that energy of faith which enables us to live constantly in the vision of the good; and let us descend, in action, into the world of fact, with that vision always before us. ${ }^{16}$

\section{Notes}

${ }^{1}$ Quoted in Jay B. Rohrlich: Work and Love: A Crucial Balance (New York: Summit Books 1980), p. 231 (original source not indicated).

${ }^{2}$ Ayala Pines and Elliott Aronson: Career Burnout: Causes and Cures (New York: The Free Press 1988), pp. $9-10$.

${ }^{3}$ Ibid., p. 53

${ }^{4}$ Ibid., p. 79.

${ }^{5}$ Ibid., p. 5.

${ }^{6}$ Hermann Hesse, "My Life: A Conjectural Biography," trans. by Denver Lindley, in Avon Book of Modern Writing, No. 3, ed. by William Phillips and Philip Rahv (New York: Avon Books 1955), pp. 5572. Original work: "Kurzgefasster Lebenslauf," Neue Rundschau, 1925. Also has appeared as "Life Story Briefly Told," in Hermann Hesse, Autobiographical Writings, ed. Theodore Ziolkowski, trans. by Denver Lindley (New York: Farrar, Straus and Giroux 1971), pp. 43-62.

${ }^{7}$ Steven J. Bartlett, “Acedia: The Etiology of Work-Engendered Depression," New Ideas in Psychology, Vol. 8, No. 3, 1990, pp. 389-396. 
${ }^{8}$ See the author's essay "Barbarians at the Door: A Psychological and Historical Profile of Today's College Students," forthcoming.

'Saint Thomas Aquinas, "Questiones Disputatae de Malo," in Questiones Disputatae (2 vols.) (Rome: Marietti 1949; original work published 1269-1272), Vol. II, p. 4; and Summa Theologiae, trans. by the English Dominican Fathers (London: Burns, Oates, and Washbourne 1912-1925; original work published 1265-1273), Part II of the Second Part, Ques. 35, Article 4, answer to the Second Objection.

${ }^{10}$ American Psychiatric Association, Diagnostic and Statistical Manual of Mental Disorders (3rd rev. ed.) (Washington, D.C.: American Psychiatric Association 1987).

${ }^{11}$ See Viktor Frankl, Man's Search for Meaning: An Introduction to Logotherapy (New York: Washington Square Press 1959) and The Doctor and the Soul (New York: Knopf 1963).

${ }^{12}$ J. H. van den Berg, The Phenomenological Approach to Psychiatry: An Introduction to Recent Phenomenological Psychopathology (Springfield, Illinois: Charles C. Thomas 1955).

${ }^{13}$ George A. Kelly, "Man's Construction of His Alternatives," Readings in Current Personality Theories, ed. Raymond J. Corsini (Itaska, Illinois: F. E. Peacock Publishers 1978), p. 121. First published in Assessment of Human Motives, ed. Gardner Lindzey (New York: Rinehart \& Winston 1956), pp. 33-61. See also Kelly's The Psychology of Personal Constructs (New York: W.W. Norton 1955).

${ }^{14}$ Ibid., pp. 123-124.

${ }_{15}$ Presented by Mircea Eliade in a symposium at the Center for the Study of Democratic Institutions, Santa Barbara, April, 1970. Relevant works by Eliade include Traité d'bistoire des religions (Paris: Payot 1949), and Aspects du Mythe (Paris: Gallimard 1963).

${ }^{16}$ Bertrand Russell, “A Free Man's Worship," in Why I am Not a Christian (New York: Simon and Schuster 1957), pp. 107-108. 